\title{
HIV/AIDS: Group versus Individual Right
}

\author{
Article by Oladimeji Akeem Akinyemi \\ Public Health, Texila America University, Namibia \\ E-mail: dimeji22@yahoo.com
}

\begin{abstract}
HIV/AIDS management keeps on evolving since its discovery, so also are the ethical issues surrounding it. Policies formulated and laws enacted by various nations also keep on changing like the mutant variants of the virus itself. International organisations (WHO, UNHCR) guidelines have been instrumental to streamline the ethical issues about HIV/AIDS worldwide. Disparities in implementation of the guidelines still exist among nations despite the guidelines. To certain extent, this may be due to cultural differences. This article explains the ethical issues on HIV/AIDS in relation to "Individual vs. Group/community rights"
\end{abstract}

Keywords: HIV/AIDS; mutant; WHO; UNHCR; ethical issues; guidelines.

\section{Introduction}

Since the discovery of Acquired Immunodeficiency Syndrome (AIDS) in 1981 and its link with Human immunodeficiency Virus (HIV) as the cause (Bragdon vs Abbot 1998), it has continued to spread like a wild fire with poor effort to put it out. It has eaten deep into the fabric of many nations with the Sub-Sahara Africa most affected. It has become a global problem and as such the word 'epidemic' is ascribed to HIV/AIDS.

According to the UNAIDS global statistics of 2015, a total of 36.7 million people are living with HIV among of which 34.9 million are adults and 1.8 million are children (less than 15 years). In the same year, 1.1 million people died of AIDS-related illnesses (UNAIDS 2016). Since the start of the epidemic, an estimated 78 million people have become infected with HIV and 35 million people have died of AIDS-related illnesses (UNAIDS 2016). An estimated 25.5 million people living with HIV live in sub-Saharan Africa. The vast majority of them (an estimated 19 million) live in east and southern Africa which saw 46\% of new HIV infections globally in 2015 (UNAIDS 2016). Around $40 \%$ of all people living with HIV do not know that they have the virus (UNAIDS Prevention Gap 2016). In 2015, there were roughly 2.1 million new HIV infections, 150,000 of which were among children. Most of these children live in sub-Saharan Africa and were infected via their HIV-positive mothers during pregnancy, childbirth or breastfeeding (UNAIDS/AIDSINFO 2016).

The factors fuelling the HIV epidemic in Sub-Sahara Africa are poverty, conflict, unemployment and illiteracy. Though, transmission also occurs among the drug users but the predominant mode of transmission in Sub-Sahara Africa is heterosexual (Murilo 2015). Few studies have been done on other modes of transmission in this region due to high level of denial, stigma and discrimination.

The epidemic affects all spheres of life with the individuals, families and nations having shares of its burden. Broadly speaking, the impacts are on the household, demographic structure, firms and economy. The health, agriculture and education sectors are not spared from the devastating effects of HIV. The health care spending (budget) of the affected nations has increased dramatically with the HIV/AIDS spending taking the greater percentage of the total health care budget. This invariably reduces budgetary spending on other sectors of the economy.

The cornerstone of controlling the epidemic is prevention and given the above scenario, the individuals, communities, nations and world at large need to be protected from the devastating effects of HIV. Protecting the individuals, communities, nations and the world in 
Texila International Journal of Public Health

Volume 5, Issue 1, Mar 2017

general against HIV is a complex issue with interplay between political, ethnic values, international relations, individuals' right and communal right.

Prior to the HIV/AIDS epidemic, the link between health policies and human rights was rarely drawn (Hnin 2010). Indeed, public health, which traditionally has employed measures that can be coercive, compulsory, and restrictive, has often been considered as one of the legitimate grounds for restricting human rights (Mann 1996).

Whenever the issue of rights come up, the traditions (norms and culture) of the community must be taken into consideration. The issue of public versus individual rights in relation to HIV/AIDS is a double edged sword that requires critical analysis and evaluation. Considering the complexity of this matter, the analysis can be bi-directional and either of the directions will be absolutely right or wrong.

There are no universally valid moral principles and that we need to look at ethical problems in non-Western countries using different set of ethical framework (Niekerk 2005). Therefore, the approach to AIDS problem in Western countries cannot be directly applied to non-Western countries, especially Africa without modifications to suit the cultural and moral values of the people. Ankra and Gostin, in their book 'Ethical and legal consideration of the HIV epidemic in Africa support this approach (Ankra et al 1994).

\section{Group vs. individual right}

The perspective with which HIV is seen regarding private right and public right to be protected against HIV will be discussed and evaluated under the following headings:

- Informed consent and confidentiality

- Compulsory/voluntary testing

- Privacy

- Disclosure

- Condom use/protection among sexual partners

- Adherence/non-adherence to ARV

- Vaccine trials

- Compulsory quarantine/isolation

\section{Informed consent and confidentiality}

Informed consent and confidentiality in respect to HIV is born out of respect for human dignity and rights. It is also the pillar on which the prevention of HIV is built. HIV is an epidemic and therefore considered as a threat to public health.

This raises a question as to whether the right be individualised or made a public right. In either of the ways, public or individual rights, there are merits and demerits. Though, the meagre resources of the affected nations especially Sub-Sahara Africa is channelled to the prevention of HIV thereby reducing budgetary allocation to other sectors of the economy. Should the scarce resources be spent on HIV at the expense of other sectors? I am of the opinion that a balance should be achieved in this regard. We should remember that "a stitch in time saves nine". The health care spending on HIV may be high presently but the end will justify the means bearing in mind the devastating effect of its negligence and denial. Neglecting the HIV issue today will lead to a vicious cycle that may eventually paralyse other sectors of the economy. For instance, the effects on households (increased orphans), firms (loss of workforce and reduced productivity), agriculture (decrease food production) and education (low literacy level).

It is tempting to clamour for abolishment of informed consent and confidentiality so as to protect the "public" against HIV. This act will prevent people from seeking medical help even for non-HIV related illness for fear of being subjected to HIV test without their consent. The consequences of this will be increased populace with ill-health harbouring both communicable and non-communicable disease without medical help with dire implication on the economy. This act therefore jeopardises the interest of the 'public' it is trying to protect. 
On the other hand, knowing quite well that their consent is needed before HIV test can be done will make people to freely present for proper evaluation and treatment. This is a good avenue for trained counsellors to discuss with people on need for routine HIV test. This subtle way respects the individual right and experience has shown to increases the number of people voluntarily testing for HIV. This provides a good and reliable source of data on the epidemic as well as education on protection and prevention of its spread by the HIV positive and negative individuals respectively.

Informed consent, counselling and confidentiality is the gateway through which people voluntarily agree to HIV testing. This also has the advantages of reinforcing positive health behaviour and also encouraging them on the need for disclosure as a way of reducing the stigma and discrimination associated with being HIV- positive.

The more people disclose their status, the lower the level of stigma and discrimination because the perspective through which people see HIV changes and it is eventually seen as one of the chronic diseases like hypertension and diabetics.

\section{Compulsory/voluntary testing}

Concerning HIV testing, the advocates of public/group right will argue for compulsory testing while the advocates of individual right will favour voluntary testing. As discussed in the page above, compulsory HIV testing will scare people from seeking medical attention from health facilities. Majority will prefer to die in silence than carrying the burden of being HIV positive. The group that we are trying to protect through compulsory testing is made up of individuals and the behaviour of the individual to a greater extent determines the rate of the spread of the disease. If the group right prevails regarding testing, then the same group must be forcefully restrained from risky behaviour that spread HIV for the compulsory testing to be justified.

What McDonald identifies in the alleged "group rights" is the fact that they are positive, rather than negative rights (McDonald 1991). He stated further that individual human rights in the liberal tradition are normally thought of as negative rights or "elbow room" or "breathing space" rights. The advocates of group rights also think of rights as positive, involving duties and not so much liberties (Niekerk 2004). But is compulsory testing a duty of everyone? Are people ready to accept this as a duty? What do we think of this when the same group we are trying to protect cannot uphold this sense of duty? They shy away from compulsory testing for fear of stigma and discrimination. For the group rights, for the compulsory testing to be effective, the issue of stigma and discrimination must be addressed. This means that the HIV positive people as a group on their own need to be protected. How many groups do we now have to protect without conflicts? At this juncture, individual rights remain the best option.

The evidences below further support individual right:

- Illinois, USA introduced mandatory reporting and contact tracing of HIV/AIDS cases and the percentage of those not appearing for appointments to be tested at Chicago's two city test centres rose from 34 percent in April to 41 percent in May to 46 percent in June (Cohen et al 1990).

- In Germany, the state government of Bavaria required mandatory testing of prostitutes and drug users, many of them moved out of the state to avoid the test, whereas others dropped out of research projects, causing the projects to close (Cohen et al 1990).

- In 1985, Australian minister of health proposed a legislation which mandated reporting of HIV-positive test results and criminalised sexual relations with people infected with HIV (unless the partner was notified prior to the relation). This led to an immediate drop in requests for HIV tests by 40 percent from August to September (Cohen et al 1990).

Given the scenarios above, voluntary testing should be the standard to respect individual rights regardless of group rights 
Texila International Journal of Public Health

Volume 5, Issue 1, Mar 2017

\section{Privacy}

There is at present a lack of systematic monitoring and worldwide assessment of HIV/AIDS-related human rights violations (UNCHR 1994). Mandatory testing without informed consent is explicitly prohibited by WHO Guidelines. Although, the right to privacy can be justifiably disregarded by governments for the greater good of protecting public health, provided the stringent conditions are met (Hnin 2010). Everyone has a right to privacy and the issue of HIV cannot be discussed in isolation. The argument in favour of group rights implies that the right of individual to privacy will be eroded. Considering the stigma and discrimination associated with the disease, people will prefer not to use health facilities for the fear of compulsory testing. This will greatly affect the control of the epidemic negatively and the magnitude of the disease will be undermined leading to grave consequences. It may lead to a vicious cycle and the solution to the epidemic may never see the light of the day.

On the other hand, individual rights that protect their privacy will indirectly lead to openness about people's HIV status. Invariably, the secrecy about HIV will soon become 'open secret' and voluntary disclosure becomes the order of the day for majority of the populace.

\section{Disclosure}

This is an important aspect of HIV prevention program. Given that stigma and discrimination are eliminated or reduced to a significant level in our society, disclosure will play an important role to step down the epidemic. Which way should disclosure discussion swing in relation to the 'group versus individual rights'? If it swings in favour of 'group rights' which means that the society /community have the 'right' to be protected against HIV then disclosure becomes mandatory. But to whom do they disclose? Should they disclose to their status to everyone at risk of contacting it from them? From the 'group right' point of view, I think they should disclose to everyone at risk. Another issue is disclosure involving children and the underage individuals. In what manner should their status be disclosed? Do the parents have the right to disclose their status on their behalf? So many questions will remain unanswered about 'group rights' in relation to disclosure.

We should also bear in mind the complexities of disclosure in our society. Some of these are discussed below:

Poverty: Disclosing the HIV status in the face of poverty is a difficult task. Considering the situation in which a financially dependent individual risks losing all benefits he/she is getting by disclosing his/her HIV status. This society is not yet ripe for that type of practice because stigmatization is deeply rooted.

Gender inequality: Gender inequality and violence against women is a problem on its own in Africa. Despite the awareness and campaign to correct this problem, it persists. In a typical African tradition, women have no right and are fully dependent on their husband. The same society accepts men promiscuity as sign of macho whereas a woman practicing same is regarded as a whore. A woman has no right to deny her husband sex and at the same time cannot negotiate safer sex. Often times men refuse to do HIV test and any woman that discloses her HIV status to the same faces discrimination. A woman that discloses her status risks losing her home and therefore faces social discrimination (regarded as an outcast) and hunger because she totally dependent on her husband. This may not be the case in some urban areas but the issue of rights must be universal and as such no segment of the society can be isolated. The proponents of 'group rights' should bear in mind the number of "social outcasts" that will result from the 'compulsory disclosure' that they thought will protect the society from the HIV scourge. The ultimate right to disclosure should lie with individual and voluntary disclosure should be encouraged and not enforced.

Stigma and discrimination: This is as old as the HIV/AIDS itself. HIV cannot be discussed in isolation without mentioning stigma and discrimination. Stigmatization is deeply rooted in people and most dreaded in HIV positive individuals. Compulsory HIV status disclosure will only increase the level of stigma and discrimination among people. Instead of wasting 
precious efforts on compulsory disclosure to protect the society, the energy should be channelled towards education and awareness programmes to eliminate stigmatization and encourage openness about HIV status.

\section{Condom use/protection among sexual partners}

The scenario given in the book 'Ethics \& AIDS in Africa, The Challenge of Our Thinking' that refusal to use safety belt while driving is a punishable offence because it endangers the live of the driver can be liken to the use of condom (Niekerk et al 2008). From the 'group rights' point of view, refusal to use condom for protection against HIV constitutes public health hazard and should be punishable. This is not possible in real life situation unless a clause is added stating that is not punishable if the individuals involved consented to the act. This again negates the purpose for which the' right' issue is intended. It invariably becomes a vicious cycle. Another bottleneck is procreation among HIV positive individuals. To protect the society or the group from HIV, the HIV positive individuals will have no right to give birth so as to avoid bringing forth HIV positive baby. This on the other hand becomes a human right issue which will further aggravate stigma and discrimination. 'The right of men and women of marriageable age to marry and to found a family shall be recognised'. (International Covenant on Civil and Political Rights, Article 23, in UN 1988) Mandatory premarital HIV testing, coupled with the denial of a marriage licence to those infected with HIV and prohibiting the marriage of individuals known or suspected to be HIV-infected, interferes with the right to marry and found a family (UNCHR 1994). A public health rationale does not provide sufficient justification for violating this right, because such a restriction does not serve as an effective means of preventing either sexual or perinatal transmission of HIV as extramarital and premarital sexual activity are common.

The hallmark in this situation is 'individual rights'. The onus to use condom lies on the individual and this should be greatly supported to encourage behavioural change. This is the way forward in the struggle to stem the spread of HIV and protect individuals thereby protecting the society indirectly.

\section{Adherence to ART}

It's a widely acknowledged fact that poor adherence to anti-retroviral drugs leads to emergence of resistance strains of the virus. The conventional/existing drugs become ineffective against the virus. This is of a great public health concern because it does not only fuel the epidemic but also increases the health care budgets. The cost of developing new drugs and its antecedent high price to the public could be better imagined.

If a "group" right is to prevail in adherence, people on ARV must protect the society/group by strict adherence to their drugs. Failure to do so should be punishable just like the use of safety belt. But the question is how do we monitor adherence? Even if it can be monitored, is it not going to discourage people from getting tested not to talk of agreeing to start ARV? I believe the goal standard regarding adherence is individual rights".

\section{Vaccine trial}

The concept of the best interests of the child is well established in international law. The Article 3 of the Convention on the Rights of the Child (1989) provides that in all actions concerning children, their best interests are of primary consideration (Niekerk et al 2008). Although, children has right to effective health care including ARV but is their enrolment in vaccine trial in their best interest? The children as a group will benefit greatly if an effective vaccine can be found but what becomes of the children used as "Guinea pig" in vaccine trials if they eventually develop the disease during trials? Is it in their best interest? This is an area that must be treated with caution. I take no side in this regard because is a very sensitive and a necessary evil one cannot avoid. Trials must be done for effective vaccine to be licensed and at the same time participants must be enrolled. The hallmark is for the researchers to adhere to the best ethical standard and refrain from frivolous researches. 
Texila International Journal of Public Health

Volume 5, Issue 1, Mar 2017

\section{Compulsory quarantine}

The legitimate ground for depriving an individual of liberty through public health measures includes compulsory quarantine or internment. This is commonly employed in cases of communicable diseases. However, such measures need to be in accordance with a procedure established by law (UNCHR 1994). The government would have to establish a case that the individual who has been detained indeed has the infection and that the detention is essential for preventing the spread of the virus. WHO recommends 'that persons suspected or known to be HIV-infected should remain integrated within society to the maximum possible extent and be helped to assume responsibility for preventing HIV transmission to others' (UNCHR 1994).

\section{Conclusion}

The group right is extremely limited as far as protection against HIV/AIDS is concerned. The HIV positive individuals and the HIV negative individuals all have rights to be protected and the summation of these are individual rights. Clamouring for group rights will only complicate the issue thus creating a vicious cycle in the overall prevention strategies of HIV/AIDS.

\section{References}

[1]. Ankrah E.M and Gostin L.O (1994) Ethical and legal considerations of the HIV epidemic in Africa. AIDS in Africa. New York: Raven Press, 547-58

[2]. Bragdon vs Abbort (1998) AIDS Treatment and Medical Technology: The Supreme Court Abandons the CDC. Bragdon vs Abbort, 524, US.624.

[3]. Cohen, R., and L. Wiseberg. 1990. Double Jeopardy: Threat to Life and Human Rights. Human Rights Internet. Cambridge, Massachusetts: Harvard Law School.

[4]. Hnin H P: International Law and the Rights of the People Living with HIV/AIDS.

[5]. http://ec.europa.eu/development/body/theme/aids/limelette/pdfs/confront_aids_chapter_05.pdf

(Accessed 23/10/2016)

[6]. Mann, J., D. Tarantola, and T. Netter, eds. 1992. 'AIDS in the World: A Global Report'. Cambridge, Massachusetts: Harvard University Press.

[7]. McDonald, M. (1991) 'Should Communities Have Rights? Reflections on Liberal Individualism', Canadian Journal of Law \& Jurisprudence, 4(2), pp. 217-237.

[8]. Murilo J. (2016) HIV Update 2015.

www.cme.baptist.net/infectionsymposium/documents/2015/presentation/murilo_1106_915.pdf

[9]. Niekerk A. A (2005) Individual versus "group" rights in the HIV/AIDS debate: does more bad news make any difference?

[10]. Niekerk A.A and Kopelman L (2008) Ethics and AIDS in Africa, the Challenge of Our Thinking.

[11]. UNAIDS (2016) Fact Sheet. www.unaids.org/en/resources/fact-sheet (Accessed 23/10/2016)

[12]. UNAIDS (2016) Prevention Gap Report.

www.unaids.org/en/resources/documents/2016/prevention-gap (Accessed 22/10/2016)

[13]. UNAIDS/AIDSINFO (2016) www.aidsinfo.unaids.org (Accessed 20/10/2016)

[14]. United Nations Commission on Human Rights (UNHCR). 1994. Report of the Secretary- General on International and Domestic Measures Taken to Protect Human Rights and Prevent Discrimination in the Context of HIV/AIDS. E/CN.4/45. Geneva, December. 